\title{
Economic Design of Competitive Balance Level for Egyptian Football League
}

\author{
Saad Ahmed Shalaby ${ }^{1}$ \\ ${ }^{1}$ Professor of Sports Marketing \& Economics at the Sport Management Departement, Faculty of Physical Education, Mansoura \\ University, Egypt
}

\begin{abstract}
The current study is trying to understand interactions between economic design of Egyptian Football league and its competitive balance level since its inception in 1948/1949 season till 2009/2010 season, the last season in which the competition was completed at the start of the study. This is done through identifying competitive balance level within seasons and time eras, then determining the extent of control and domination of some teams on the competition in the long term. The researcher employed descriptive method (analytical studies). Research sample included (54) season divided into time eras, each era consisted of (9) full seasons.

The results showed a trend towards an increase in competitive imbalance for Egyptian Football League Championship through first three eras, in addition to recurrence between increasing and decreasing in competitive balance level within time eras during the last three eras. This study opens the way for further economic researches on professional competitions with proposing new development trends and linking between theoretical and empirical economic studies.
\end{abstract}

\section{Introduction}

L eague championship is the main market for products in professional football teams' industry in most countries of the world. In all world countries, there is an important major championship where professional teams compete. Sports economists agree on that fact and do not look at the single tournament which numbers of teams participate in its production as a competition resistant behavior. Therefore, we find that all national football associations have a major championship monopolizing the market, where leagues are structured in a hierarchy starting from low divisions to first or premier division, which lie on hierarchy top and monopolize the market.

This tournament is strongly controlled by the national association, or his representative, whether a committee or association, which in turn considered responsible for managing the competition (where number of teams/clubs participate in). Number of participating clubs/teams in the tournament is one of the main challenges for the association because it's fixed to some extent, and can only be changed by a formal agreement between participating clubs in the competition, or the Association.

Here, the key issue for competition industry is determining the appropriate number of teams to produce a balanced championship in manner makes it more interesting to consumers (viewers- attendance - sponsors ...... etc.), mostly when top clubs seek to preserve the current form of Championship and prevent new participants from entering the competition, especially when there are commercial rights sold collectively plus revenues ' redistribution on all participating teams in the tournament (Kesenne .2007a).

Associations take this challenge into account by adopting system of promotion and relegation, where some teams are relegated to the bottom or to the following class in the hierarchy and prompting Champions of that class to the upper class, to break the monopolistic practices in the broader market. Here we find that system of promotion and relegation creates incentives for teams in low classes to provide the best performance to climb into premier class and achieve better financial revenues from tournament collective sales by a way that does not cause a malfunction in the championship's competitive balance level (Kesenne .2007b).

In professional sports associations, we often argue that any little competitive balance leads to increased dominance of big teams on small teams, whenever competitive balance level became higher; professional associations' competitions become more attractive for fans and viewers. So, professional associations adopted various forms of relegation and promotion systems, revenues' sharing, applying salary cap rules, as well as sports talents' retention in an attempt to correct the apparent lack of competitive balance, which has become one of the most series and important topics in football industry. Each of fans, media and sports associations stress on competitive balance importance because of its role in achieving fans' satisfaction and welfare, and its relation with broadcasting 
and gate revenues, which affect on financial stability of football brands (Soebbing .2008)

Competitive balance refers to fans' rational expectations about who will be the winner in any fully balanced competition, where we find that each participant starts with equal and balanced chance to win, so here the result is totally uncertain. But in case of competitive imbalance, this will enable fans to predict the final outcome with one probability, and thus fans will lose their interest in the competition (Szymanski, 2010).

The presence of some degree of competitive balance in football competitions consider a necessary and essential feature to increase the attractiveness of participating teams in league matches, because any kind of increasing in competitive imbalance with time will have severe damage on the sustainability and survival of the competition.

\section{Literature Review}

Given the size and popularity of football industry, which enable it on generating approximately (3\%) of world trade, researchers have conducted many researches related with economic design for football competitions, but nonetheless remain limited somewhat compared with economic activities in other areas. Such researches handled with football economics as a branch of professional team sports', and these economic studies dealt specifically with football teams as competitive businesses, especially cases related with: market demand on sporttransfer market - market structure - broadcasting revenues ... etc.

Bourg (2004), aimed to identify the level of competitiveness justice in the five major leagues (England- France- Germany- Italy-Spain), in the period from beginning of 1980 s till beginning of the new millennium, where most important results showed increase in competitive imbalance in France and Germany, on the contrary, there was a decrease in competitive imbalance in England, Spain and Italy.

Halicioglu (2006), aimed to identify statistical justifications for introducing a new points' system in football competitions to increase competitive balance level, and the study showed a clear statistical improvement in competitive balance level after the introduction of the proposed points' system, which is: (4) points for a win- (2) points for a draw- (1) point for a loss versus traditional existing system.

Kringstad and Gerrard (2007), which aimed to identify competitive balance level in the period (1966-2006) in ten European leagues, the results showed a reduction in competitive imbalance level during the first ten years (1966 to 1976) compared with competitive imbalance level during last ten years (1996-2006) with the exception of the Italian league.

Soebbing (2008), Feddersen \& Meaning (2008) who aimed to identify competitive balance rate using SDWP (SDWP) and Humphries method for measuring concentration rate of competitive balance and competitive balance index known as Herfindahl-Hirschman Index (HHI), the results showed strong differences in concentration rate of competitive balance among the five major European football associations, where English and French Associations were the best in competitive balance level while Spanish Association was the least in terms of competitive balance.

Szymanski (2010), aimed to identify competitive balance level in English Premier League during the period (19771999), where he used ideal standard deviation (ISD) in measuring competitive balance level, the results showed in end of 1980s there was an increase in imbalance between the English league teams' followed by a decline in competitive balance level.

Szymanski (2010), aimed to identify the relationship between disparity in revenues and competitive balance and games' attraction in team sports, results showed reduction in competitive balance level in Cup championship, which was reflected in public attraction where attendance rate declined by $(45 \%)$ from league championship rate, and this illustrates the disparity in revenues' central distributions for television broadcasting rights.

Fort (2012), which targeted tracing uncertainty of outcome hypothesis $(\mathrm{UOH})$ for end of the season in the period (1922-2010) for NFL in USA, with using Ratio of Standard Deviations (RSD), the results showed that there was really only one episode of truly awful balance, it is the 6-year string 1924-1929 (RSD range 1.90-2.24). While there have been trouble spots, like the 3-year period 19411942 and 1944(RSD range 1.99-2.29).

Shalaby (2013), which aimed to understand the relationship between fair distributions of television broadcasting revenues with competitive balance of Egyptian football League, where results showed a low level of winning percentage balance among participating teams in league championship, 2010/2011 season, a result for teams' not having strong talents and absence of fair schemes in distributing revenues of broadcasting rights' collective sale, which reflected on distributing talents on teams in a balanced manner. In addition to big markets' teams ability on generating significant financial revenues due to high demand within team's geographical scope or in the Egyptian market as a whole, this also has led competitive imbalance in competition. 


\section{Study Problem}

Competitive balance in professional leagues has become a controversial issue among large number of parties related to football industry as: lawmakers- antitrust authoritiesresponsible for arrangements and procedures for sharing revenues of television broadcasting collective rights' and sponsorship, who can enhance competitive balance level (Szymanski and Kesenne ,2010). It have been acknowledged by the European Court of Justice that there is a need for a reasonable level of competitive balance, where the Court recommended that any professional league can flourish only in the presence of clear degree of competitive balance between participating clubs (Halicioglu .2006).

Structural differences (number of teams - relegation and promotion - retaining playing talents... etc) of Egyptian Football League since its inception in 1948/1949 season have affected on competitive balance level of the major championship in Egyptian football, in which good level of competitive balance increases the levels of fans' uncertainty in outcomes of games- season and the league as a whole, and thus have a positive impact on demand levels from various consumers.

So far, this aspect has not been explored in the Egyptian football competitions, especially Premier League championship, thus it is not determined whether number of produced matches during that championship with its image and design throughout its history have been able to achieve reasonable competitive balance levels, and consequently achieving reasonable degrees of uncertainty in outcome that could enhance consumption, and in particular enhancing demanding on live viewing inside stadiums and on televisions after that championship had seen the absence of the crowds inside stadiums, in addition to tournament's commercial revenues facing a lot of challenges towards growth and development.

Competitive balance consider one of the issues that attracted economists' and politicians' attention in past and present within football industry since Rothenberg (1956) conducted studies on competitive balance, where he emphasized that any tournaments' profits decreases with decline in competitive balance and the absence of contest uncertainty (Fort, 2012).

So the actual problem facing Egyptian Premier Football League is the trend of some teams towards self-interest behavior and competition domination for the extent that may lead to lower demand and declining interest (of: fans, media, sponsors) on small teams, and so effect on Championship's collective profit as a natural result of decline in competitive balance level.
Therefore, this current study is trying to understand the interactions between economic design of Egyptian Football league and its competitive balance level since its inception 1948/1949 season till the last season in which the competition was completed at the start of the study, it's 2009/2010 season, through identifying competitive balance level within seasons and eras, then determining the extent of control and domination of some teams on the competition in the long term.

\section{Study Hypotheses}

1. There are differences between eras in competitive balance level for winning percentage of Egyptian football league.

2. There are differences between the different seasons in competitive balance level for winning percentage of each season separately.

3. There are differences in competitive balance level for winning percentage in championships of each participating team in the tournament.

\section{Study Tools}

The study relied on documents and records of the Egyptian Football Association, which includes data of matches' results for Premier League competition, for seasons 1948/1949: 2009/2010, where the data included total number of points obtained by teams, in addition to number of games won by each team during the season. The researcher excluded un-completed or canceled seasons during that period under study, they were ten seasons (1951/1952, 1954/1955, 1967/1968, 1968/1969, 1969/1970, 1970/1971, 1971/1972, 1973/1974, 1989/1990, 2011/2012).

\section{Study Methodology}

This study employed a descriptive approach (analytical studies), and this is a worthwhile research approach depends on collecting information regarding the number of winning times and winning percentage for participating teams in the Egyptian league championship that has been secured through documents and records of Egyptian Football Association. Researcher choice is justified by that Egyptian league is independent competition with highly privacy nature terms of space and time in addition to relegation and promotion from the lower grades.

This helps decision makers in designing Egyptian league to understand competitive balance level across different eras during each season in addition to competitive balance level for each team, and this opens the way for further research in this trend and proposes new trends for 
developing and linking between theoretical and empirical economic studies.

\section{Study Society and Sample}

Study population included Egyptian football league competitions since its inception in 1948/1949 to 2009/2010 season as the last season in which the competition was completed at the start of the study, the sample was chosen in comprehensive manner of all completed competitions with excluding un-completed or canceled seasons, they were ten seasons (1951/1952, 1954/1955, 1967/1968, 1968/1969, 1969/1970, 1970/1971， 1971/1972， 1973/1974， 1989/1990, 2011/2012). Research sample reached (54) season divided into eras, and each era consist (9) full seasons.

\section{Results Interpretation}

First Hypothesis: There are differences between eras in competitive balance level for winning percentage of Egyptian football league.

Table 1

Standard deviation, Ideal standard deviation and Relative standard deviation of competitive balance level for winning percentage of Egyptian football league championship according to time era

\begin{tabular}{|c|c|c|c|c|}
\hline Time Eras & $\begin{array}{c}\text { Total Teams } \\
\text { in Time } \\
\text { eras }\end{array}$ & $\begin{array}{c}\text { Standard } \\
\text { Deviation } \\
(\text { SD) }\end{array}$ & $\begin{array}{c}\text { Ideal } \\
\text { Standard } \\
\text { Deviation (ISD) }\end{array}$ & $\begin{array}{c}\text { Relative } \\
\text { Standard } \\
\text { Deviation (RSD) }\end{array}$ \\
\hline $1948 / 19491958 / 1959$ & 102 & .161918 & 0.0481 & 1.09 \\
\hline $1959 / 19601973 / 1974$ & 126 & .183421 & 0.049 & 1.373 \\
\hline $1974 / 19751982 / 1983$ & 136 & .180158 & 0.0463 & 1.401 \\
\hline $1983 / 19841992 / 1993$ & 117 & .180581 & 0.0501 & 1.302 \\
\hline $1993 / 19942001 / 2002$ & 129 & .158787 & 0.0419 & 1.202 \\
\hline $2002 / 20032010 / 2011$ & 133 & .169264 & 0.044 & 1.301 \\
\hline
\end{tabular}

Table (1) shows using various methods for estimating competitive balance of Egyptian Football League, and it includes: standard deviation of winning percentage (SDWP)- ideal standard deviation (ISD: standard deviation divided by the square of games' average in the season in each era) to compare between eras, as well as relative standard deviation (RSD: standard deviation divided by (0.5) divided by the square of games' average in the season in each era), where the table shows high value of SDWP during seasons 1959/1960 to 1973/1974 with (0.183421), and the lowest value for seasons $1993 / 1994$ to $2001 / 2002$ was $(0.158787)$.

Taking into consideration number of teams, we find that the larger ISD during seasons 1983/1984 to 1992/1993 have been affected with the decline in games' number in that era, while RSD increased of one for 1948/1949 to 1958/1959 seasons, which indicates balance in winning percentages in that era.

Table 2

Analyzing variance composites for winning percentage of Egyptian football league championship according to time era

\begin{tabular}{|c|c|c|c|c|c|}
\hline & $\begin{array}{c}\text { Squares' } \\
\text { Sum }\end{array}$ & $\begin{array}{c}\text { Degrees of } \\
\text { freedom }\end{array}$ & $\begin{array}{c}\text { Average of } \\
\text { squares' Sum }\end{array}$ & F & Sig. \\
\hline Between Eras & .282 & 5 & .056 & 1.886 & .094 \\
\hline Inside Eras & 22.027 & 737 & .030 & & \\
\hline Total & 22.309 & 742 & & & \\
\hline
\end{tabular}

Table (2) shows the results of analyzing variance composite to test the presence of significant difference for winning percentage during the eras, where variance composite analysis showed tendency to significant differences between winning percentage average with difference of Egyptian football League eras at significance level $(10 \%)$, where $(\mathrm{F}=1.886)$ and tabular value (Sig. $=$. $0.094)$ lower than the level of significance $(10 \%)$.

Table 3

Standard deviation and relative SDWP deviations of $(0.5)$ according to time era

\begin{tabular}{|c|c|c|c|}
\hline Time Eras & Number of Teams & $\begin{array}{c}\text { Standard Deviation } \\
\text { (SD) }\end{array}$ & $\begin{array}{c}\text { Relative Standard } \\
\text { Deviation (RSD) }\end{array}$ \\
\hline $1948 / 19491958 / 1959$ & 102 & 0.206195 & 1.388314 \\
\hline $1959 / 19601973 / 1974$ & 126 & 0.22274 & 1.666835 \\
\hline $1974 / 19751982 / 1983$ & 136 & 0.246428 & 1.915879 \\
\hline $1983 / 19841992 / 1993$ & 117 & 0.255496 & 1.842407 \\
\hline $1993 / 19942001 / 2002$ & 129 & 0.221312 & 1.67575 \\
\hline $2002 / 20032010 / 2011$ & 133 & 0.221591 & 1.703678 \\
\hline
\end{tabular}


Table (3) shows SD and RSD for winning percentage of (0.5) Egyptian football league according to era, the table shows high value of SDWP of 1983/1984 to 1992/1993 seasons, where SDWP average reached (0.255496). Table also shows reduction in relative SDWP for (0.5) during
$1948 / 1949$ to1958/1959 seasons, where RSD reached (1.388314), and this reflects that this era is the best in terms of competitive balance level of Egyptian league according to RSD level of winning percentage from optimum value (0.5).

Table 4

Analyzing variance composites for winning percentage deviation of (0.5) according to time era for Egyptian football league championship

\begin{tabular}{|c|c|c|c|c|c|}
\hline & $\begin{array}{c}\text { Squares' } \\
\text { Sum }\end{array}$ & $\begin{array}{c}\text { Degrees of } \\
\text { freedom }\end{array}$ & $\begin{array}{c}\text { Average of } \\
\text { squares' Sum }\end{array}$ & F & Sig. \\
\hline Between Eras & .043 & 5 & .009 & 3.625 & .003 \\
\hline Inside Eras & 1.729 & 737 & .002 & & \\
\hline Total & 1.771 & 742 & & & \\
\hline
\end{tabular}

Table (4) show the results of analyzing variance composites for RSD of winning percentage (0.5) according to era for Egyptian Football League, where table show significant differences between eras in winning

percentage average deviations of (0.5) at significance level $(5 \%)$, where $(\mathrm{F}=3.625)$ less than significance level $(5 \%)$.

Second Hypothesis: There are differences between the different seasons in competitive balance level for winning percentage of each season separately.

Figure 1

Time-series for SDWP for each season in Egyptian Football League

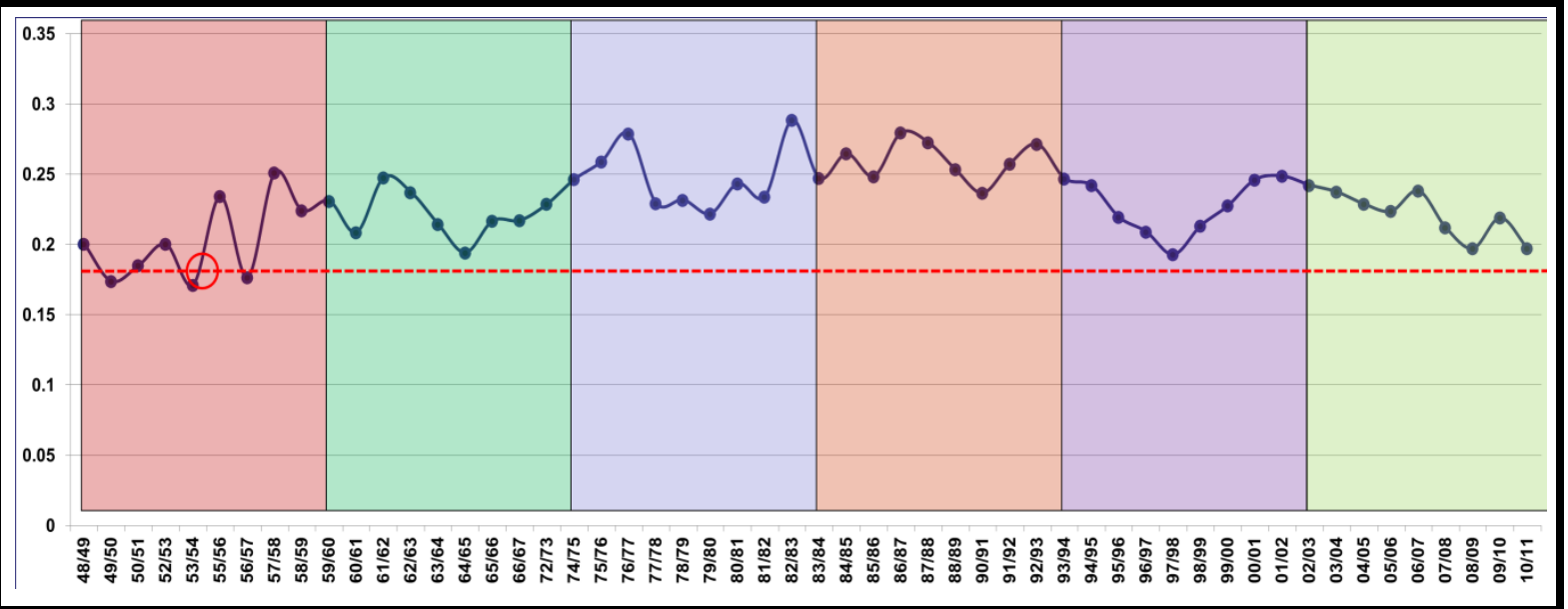

Figure 2

Time-series for SDWP from (0.5) for each season in Egyptian Football League

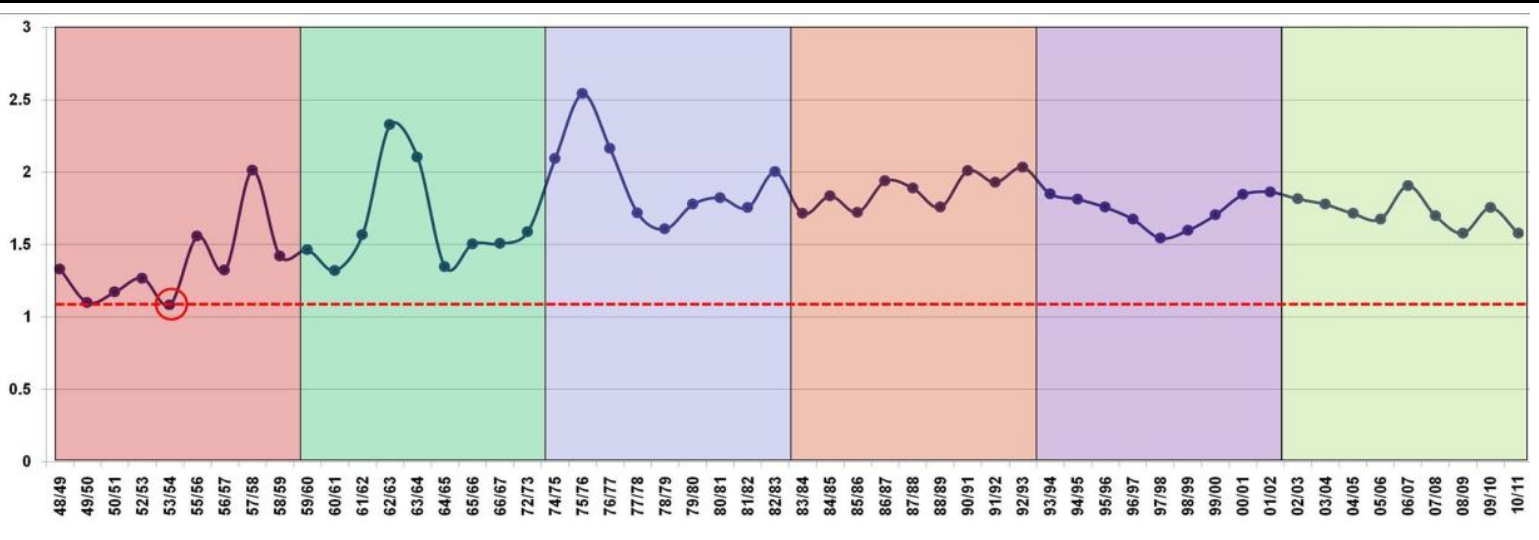


Figure (1) shows time series for SDWP according to season in Egyptian Football League, also Figure (2) presents Time-series for SDWP from (0.5) according to season. Figure (1) shows that the lowest value of standard deviation was in1953/1954 season, where SD value was (0.1712), meaning that there is a competitive balance to some extent to be close to half, while the value of RSD of
(0.5) to (1.08276) as it approaches to one as illustrated in Figure (2). Figure (1) and (2) showed trouble spots for SD and RSD between the ups and downs significantly for seasons beginning from the $1954 / 1955$ to $1978 / 1979$, in the contrary, it is clear the retreat of tension in value of SD and RSD with 1980/1981 season.

Table 5

Analyzing variance composites for squares' Sum of winning percentage deviation of (0.5) according to season

\begin{tabular}{|c|c|c|c|c|c|}
\hline & $\begin{array}{c}\text { Squares' } \\
\text { Sum }\end{array}$ & $\begin{array}{c}\text { Degrees of } \\
\text { freedom }\end{array}$ & $\begin{array}{c}\text { Average of } \\
\text { squares' Sum }\end{array}$ & F Sig. \\
\hline Between Seasons & .106 & 53 & .002 & .793 & .854 \\
\hline Inside Seasons & 1.768 & 699 & .003 & & \\
\hline Total & 1.874 & 752 & & \\
\hline
\end{tabular}

Table (5) show the results of analyzing variance composites for winning percentage deviations sums of (0.5), where table does not show significant differences between winning percentage deviations averages of (0.5) with difference in seasons at significance level (5\%),

where $(\mathrm{F}=0.793)$ and $(\mathrm{Sig} .=0.854)$ more than significance level $(5 \%)$.

Third Hypothesis: There are differences in competitive balance level for winning percentage in championships of each participating team in the tournament.

Figure 3

Time-series for SDWP for each participating team in Egyptian Football League

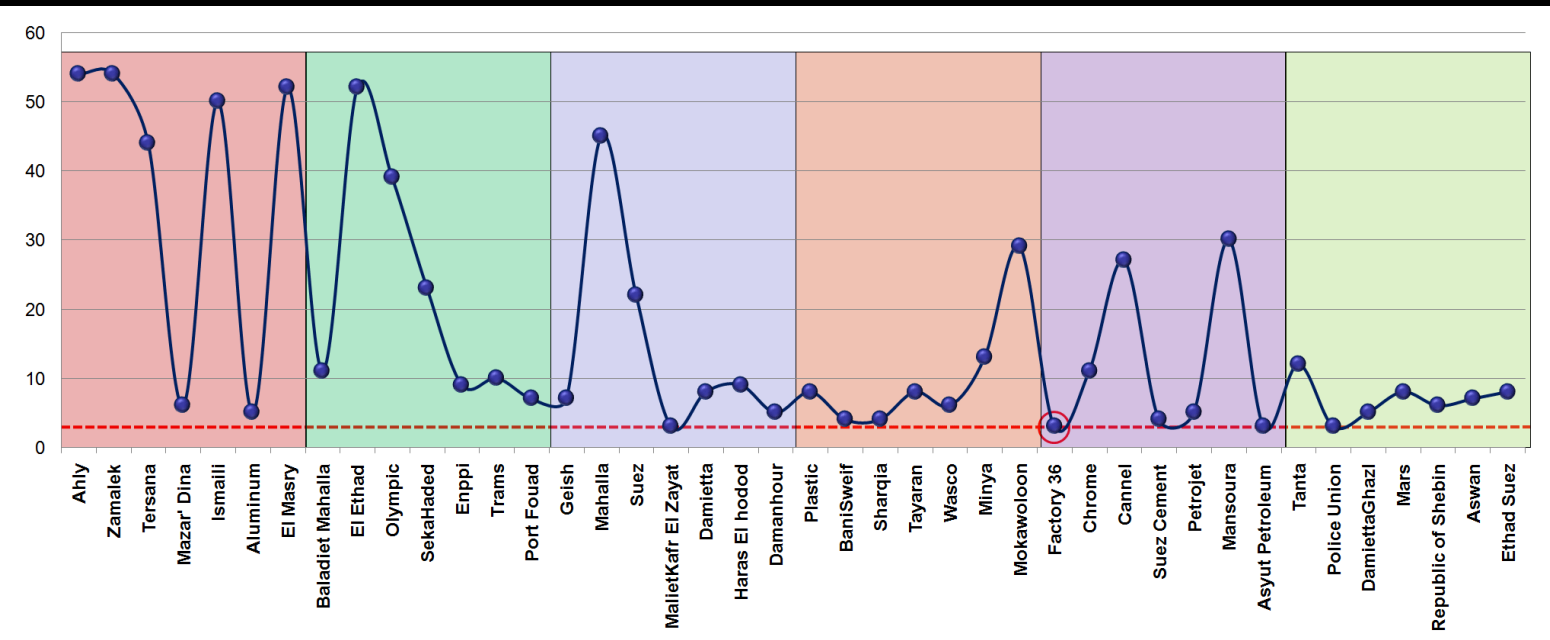




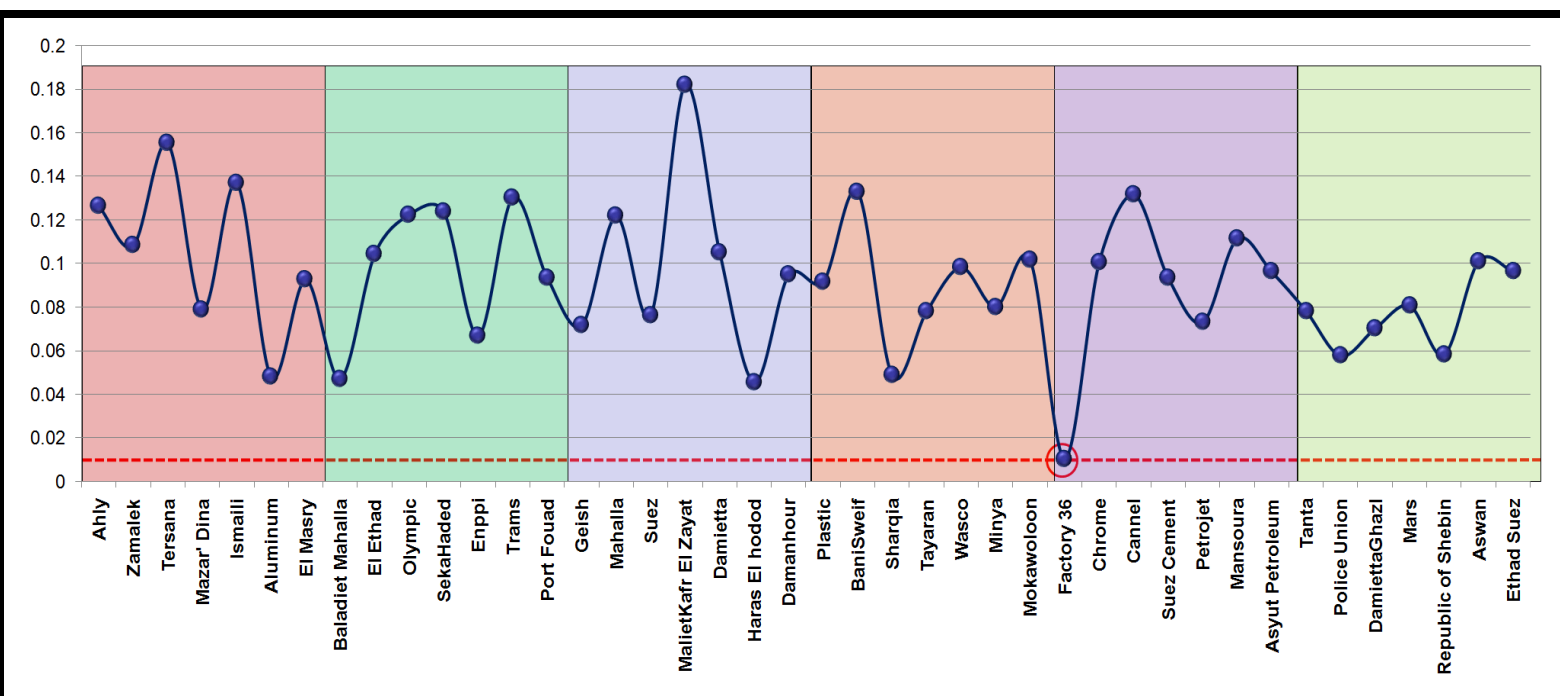

Figures (3) and (4) showed SDWP for each participating team in Egyptian Football League during 1948/1949 to 2010/2011 seasons, where table shows that the lowest standard deviation goes to Factory 36 team with
(0.010530), then Aluminum team with (0.048004), and they are values indicate to lack of competitive balance between the championship teams as value close to zero.

Table 6

Analyzing variance composites for squares' Sum of winning percentage deviation of (0.5) according to team

\begin{tabular}{|c|c|c|c|c|c|}
\hline & $\begin{array}{c}\text { Squares' } \\
\text { Sum }\end{array}$ & $\begin{array}{c}\text { Degrees of } \\
\text { freedom }\end{array}$ & $\begin{array}{c}\text { Average of } \\
\text { squares' Sum }\end{array}$ & F & Sig. \\
\hline Between Eras & 13.738 & 53 & .259 & 20.836 & .000 \\
\hline Inside Eras & 8.571 & 689 & .012 & & \\
\hline Total & 22.309 & 742 & & & \\
\hline
\end{tabular}

Table (6) shows results of analyzing variance composites for winning percentage deviation sums' of $(0.5)$ for each participating team in the tournament, the table showed significant difference between winning percentage average with difference teams at significance level (0.5), where $(\mathrm{F}=20.836)$ and $($ Sig. $=.000)$ less than the significance level $(5 \%)$, so there is differences in winning percentage deviations from optimum value (0.5) according to different teams.

\section{Results Discussion}

First hypothesis: There are differences between eras in competitive balance level for winning percentage of Egyptian football league.

The results of this study indicate to a trend toward an increase in competitive imbalance in Egyptian football league across the three first eras, in addition to recurrence towards increasing and decreasing in competitive balance level between time periods during the three past eras.

Feddersen and Meaning (2008) mentioned that English and Italian Premier League had a clear trend towards competitive balance beginning $1948 / 1949$ to $1958 / 1959$, also the results of Fort (2012) who indicated that 1950s from (1952) to (1957) had witnessed a better level of competitive balance ever in NFL where RSD ranging between (1.2) to (1.49), the researcher refers that due changes happened in competition design and constant change in teams' numbers that produce competition through every era, especially in early stages of the competition, and this confirms number of games into account at measuring competitive balance level using RSD that led to significant differences in competitive balance level for winning percentage during the eras, where $1948 / 1949$ to $1958 / 1959$ era had the best level of competitive balance that was close to one.

These results due that all teams in that era 1948/1949 to 1958/1959 with the inception of the Egyptian league invested the same amount of resources in players trying to win the championship, and then providing equal opportunities for each team to win. And this agrees with Szymanski and Késenne (2010) in that when teams participate in a contest with the same equal production capacities of talent (players), it's expected from each talent unit to produce equal winning chances. 
The results indicate that in the following eras, there was a tendency to increase imbalance, as a result to that big market teams' were able to increase demand size as a result of successes in championships in first era and increase its financial resources and enhance their ability to attract a large audience and control talents' markets (players), in addition to reduced demand for the teams that did not achieve a great deal of success during the same era, Subsequently they were unable to attract a large audience and had small markets as a result of inability to attract outstanding talents, which led to their exit from market's main competition (Premier League) during the following eras.

This is consistent Shalaby (2013) results, in that reduction in competitive balance level in 2010/2011 season is due to that championship teams' do not have equal playing talents because big markets' teams become able to generate significant financial revenues due to high demand on them within geographical scope for team and market as a whole.

This is consistent with Soebbing (2008) in that sports teams aimed at winning maximization are seeking to acquire the best talent to ensure continued control of viewing markets. This is also consistent with Szymanski (2010) that the growth of financial disparities within English football League divisions which led to large, clear increase in imbalance level in and between seasons from (1977) to (1998).

Second Hypothesis: There are differences between the different seasons in competitive balance level for winning percentage of each season separately.

This study results' showed that there is difference in competitive balance level according season, where competitive balance level in 1953/1954 season was the best ever in terms of value of SD and RSD of winning percentage for (0.5), as well as the results showed that there is an improvement of SD value for winning percentage as a measure of competitive balance level beginning 1992/1993 to 2010/2011 season, though with the beginning of $(2000 / 2001)$ era, it was representing trouble spots towards increasing competitive balance level.

These results are due to number of teams and monopoly spatial (geographic) characteristics of participating teams in 1953/1954 season, where participating teams were able to produce few games during the season and enjoys a high level of loyalty from the public, and then impact on high demand on live viewing inside sports stadiums, which were the main source of revenue for sports clubs (football teams), and thus, those clubs possess capabilities equal to some extent to attract outstanding players and retain them for long seasons because of applied retention rules, and thus improve competitive balance level for the season a natural result of increasing desire to win and continue to attract a large number of teams' fans.

In addition to that, teams were from limited geographic scope, and that contributed in strengthening their ability to apply monopolistic practices' rules to attract the best talents, and this confirms that with the breadth of competition on best talents and the emergence of new financial resources in recent seasons, teams have not been able to continue on a regular basis in the main competition in recent twentieth seasons, such as Olympic and Tersana, though their ability to win the competition during early seasons of league competition.

This consistent with Szymanski (2010) defense of retention rule, in which it was a necessity for fair and equal talents' distribution between competing teams to maintain a reasonable level of competitive balance, to strengthen consumer desire (fans) in paying fees to get into the game.

Third Hypothesis: There are differences in competitive balance level for winning percentage in championships of each participating team in the tournament.

Study results indicate to a lack of competitive balance between championship teams', where SDWP value for some teams approaching zero. This goes back to that those teams had the least number of participations in the tournament and thus number of games, where they were always affected by relegation and promotion system from minor leagues to premier league championship, promoted to premier league and relegated again, they are teams belongs mostly to companies such as clubs (Factory 36Aluminum- Mazar' Dina- Maliet Kafr El Zayat- Suez Cement ... etc.), where they always suffered from low level of support from fans in the local and national level, which is reflected on their ability to retain and invest in top talents, and therefore always be vulnerable to a decline in demand for live viewing inside stadiums or later on television screens.

This is in addition to that relegation and promotion system did not include providing financial support from sports competition to enhance their ability to buy and employ outstanding talents. This consistent with Szymanski (2010) in that relegation and promotion system lead to talents' spread across the teams and thus lower the quality of play.

In contrast, standard deviation had increased of winning percentages for the majority of teams that have enjoyed great loyalty in geographical scope that belong to it, and were able to build bases of fans at the local, regional and national levels, such as teams (Ahly- Zamalek- Ismaili- El Masry- El Ethad- Mansoura- Olympic), which reflected positively on their financial resources. This indicates that those teams were able to control the 
championship in the long term and this is known as uncertainty level in outputs, i.e. monopoly of the first positions in the tournament, and thus those teams were able to generate financial revenues from live audience, then broadcasting revenues later, either through individual or collective sales.

This led to their controlling on top prepared talents (bought from other teams in the competition), preparing inner talents through junior sector, this is confirmed from that most of those teams had won the league title, this is known at sports economists as enhancing direction towards winning. This is consistent with Soebbing (2008) that teams with low-revenue curve choose less winning percentage from teams with high-revenue curve, and this reflects the disparity in winning percentage and therefore competitive balance level.

The results showed that teams that belong to institutions with large financial capacities, such as (Haras El hododMokawoloon- Enppi- Petrojet) were able to be in intermediate position in terms of SDWP value among both previous groups, who invested large sums of money in talents' preparation through juniors sectors, in addition to contracting with outstanding talents, and thus be able to win the championship or achieving advanced positions in competition in some cases, such as Mokawoloon. Therefore, adopting a winning strategy as the second group, or enhancing profit principles through selling distinguished talents to big teams which have enjoyed great financial capabilities and high levels of public support, such as Ahly- Zamalek. This is consistent with Szymanski (2010) which confirms that there is a close relationship to some extent between team's success and relative spending on wages.

\section{Conclusions}

1. Measuring competitive balance level for Egyptian Football League Championship with various forms of standard deviation used in the study (SD- ISD- RSD), because number of games and number of participating teams in the tournament play an important role in estimating competitive balance level for (time period season - team).

2. Regional loyalties of geographical team's scope play an influential role in assessing competitive balance level of Egyptian Football League Championship for (time period - season - team).

3. Financial capacities, relegation and promotion system, demand size on live viewing inside stadiums and in front of television screens, lead to improve competitive balance of Egyptian league contest.
4. Big teams' control on sports talents lead to increasing imbalance in competitive balance level for Egyptian Football League Championship, and this lead to various forms of economic performance for teams, where some teams move towards enhancing targets related with profits instead of enhancing targets of winning.

\section{Recommendations}

1. Egyptian Football Association should take into account the economic design of competitive balance level for league championship through using different measurement methods within time eras and during seasons, and defines mechanisms that limit the control of some teams on the tournament, to enable competition on improving its competitive balance and increase commercial revenues.

2. Egyptian Football Association should reconsider in designing relegation and promotion system, with creating teams that enjoy regional and national loyalties to enable them to develop and increase number of teams' fans and the competition as a whole, and not exceeding (16) teams in the competition.

3. Egyptian Football Association should establishes centers for distinguished talents to be nucleus to support sports teams that has limited financial capabilities to invest in distinguished talents, and identifying a new mechanism to ensure fair distribution of sports talents on competition teams, and not monopolizing big teams on the market, and thus reducing demand for the competition as a whole.

\section{References}

1. Bourg, F. (2004). Professional team sports in Europe: which economic model? in: Fort, R. and Fizel, J. (eds.) International sports economics comparisons. London: Praeger.

2. Feddersen, A. \& Meaning, W. (2008). The European Perspective on Team Ownership, Competitive Balance, and Event Impacts. In Himphreys, B \& Howard, D. (2008). Business of Sports (volume 1). Praeger. London.

3. Fort, R. (2012). Competitive Balance in the NFL. In Quinn, K. (2012). The Economics of the National Football League. Springer. London.

4. Halicioglu, F. (2006). The impacts of football point systems on the competitive balance: evidence from some European football leagues. MPRA. Muenchen.

5. Kesenne, S. (2007a). The Economic Theory of Professional Team Sports. Edward Elgar, Cheltenham, UK.

6. Kesenne, S. (2007b). The peculiar international economics of professional football in Europe. Scottish Journal of Political Economy. Scotland. 
7. Kringstad, M. and Gerrard, B. (2007). Beyond competitive balance. in: Parent, M. \& Slack, T. (2007.) International perspectives on the management of sport. Burlington, MA: Butterworth-Heinemann.

8. Rottenberg, S. (1956). The baseball players' labor market. J Polit Econ 64:242-258

9. Shalaby, S. (2013). Measuring Fair Distribution of Broadcasting Revenues and its Relationship with Competitive Balance Level of Egyptian Football League. Assuit Journal of Sport Science and Arts (AJSSA). Faculty of Physical Education - Assuit University. Egypt. 42-66.

10. Soebbing, B. (2008). Competitive Balance and Attendance in the Sports Industry. In Himphreys, B \&
Howard, D. (2008). Business of Sports (volume 2). Praeger. London.

11. Szymanski, S. (2010). Income Inequality, Competitive Balance and the Attractiveness of Team Sports: Some Evidence and a Natural Experiment from English Soccer. In Szymanski, S. (2010). ). Football Economics and Policy. Palgrave Macmillan. UK.

12. Szymanski, S. (2010). The Economic Design of Sporting Contests. In Szymanski, S. (2010). The Comparative Economics of Sport. Palgrave Macmillan. UK.

13. Szymanski, S., Késenne, S. (2010). The Competitive Balance and Gate Revenue Sharing in Team Sports. In Szymanski, S. (2010). The Comparative Economics of Sport. Palgrave Macmillan. UK. 